\title{
Coding, SDGs and Education: How Canada is preparing the next generation for global citizenship - An interview with Zoë Decker
}

\author{
Entrevistador: Cláudio Antônio Klaus Junior ${ }^{1}$ \\ Submetido em 18 e aprovado em 25 de junho de 2020.
}

\begin{abstract}
The interview is with Zöe Decker, Masters in Geology, a professional working with the Global Goals after a diverse study experience in Canada, Iceland and South Africa. Zöe now shared the mission of teaching digital literacy to all kids with the organization which she works for Kids Code Jeunesse. In the interview, she gives her personal viewpoints on coding, SDGs and education explaining how Canada is preparing the next generation for global citizenship. During the interview much of the work, mission and goals of Kids Code Jeunesse is explained.
\end{abstract}

Keywords: Coding. Global Goals. Canada.

Zoë Decker was born and raised in Calgary, Canada. She attended the University of Calgary, where she received her undergraduate degree in geology in 2014. Immediately after, she moved to Reykjavik, Iceland to pursue a Masters in Geology. Her Masters degree was focused on geochemistry and the processes that occur during a volcanic eruption. Her favorite things to do in Iceland were to sit in hot tubs, swim at the pool and eat ice cream. In 2016, after receiving her Masters degree in Iceland, she moved to Cape Town, South Africa to do research at the University of Cape Town. Her favorite thing to do in Cape Town was to go to the farmers market to buy fresh local food and walk around in the warm weather. In 2018, she returned to Canada and started working at Kids Code Jeunesse in Calgary. She still lives in Calgary, where she was born, but she'd love to move to the province of British Columbia, Canada where it's much warmer than Calgary - especially because she said she loves growing vegetables outside. Zöe is a great expression of what multiculturalism means. She also loves to knit and is currently learning french and javascript because she intends to pursue a career in web development in the future. "The future is full of possibilities!" says Zöe. 


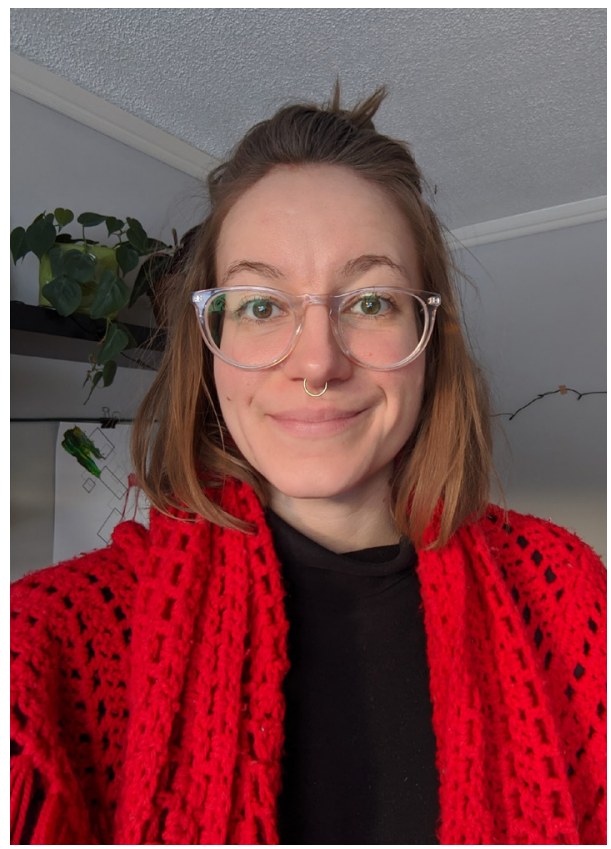

Zoë, could you please tell me more about how you came in touch with your current work?

My background is actually in geoscience and I'd just returned to Canada from a couple years of living in South Africa doing research in Cape Town. Once I came back to Canada, I knew I wanted to go into technology because that's definitely the way the world is heading. I saw a posting for an instructor position at Kids Code Jeunesse and was hired. I didn't know a lot about coding but I believed in their message of teaching digital literacy to all kids, students and teachers across the country. I knew that coding and access to technology is important for all and I wanted to be part of that.

Kids Code Jeunesse is a Canadian bilingual charity dedicated to empowering kids, teachers, and parents with technology, do you rely on governmental support, or what kinds of resources are used to keep the organization working? 
Good question. We rely a lot on funding from the federal government through the CanCode Grant, as well as other provincial government grants. We also work hard to receive funding from other businesses that believe in our message as well and want to support us.

The CanCode Grant is a program that was launched in 2017, with funds starting to flow in January 2018. Canada's government has helped provide 1.9 million experiences in coding and digital skills training to Canadian students and 96,000 teachers thanks to CanCode. CanCode aims to equip Canadian youth, including traditionally underrepresented groups, with the skills they need to be prepared for further studies, including advanced digital skills and science, technology, engineering and math (STEM) courses, leading to the jobs of the future. Canada's success in the digital economy depends on leveraging our diverse talent and providing opportunity for all to participate — investing in digital skills development will help to achieve this.

Canada's government sees this investment as a very important thing because they believe innovation begins with skilled, talented and creative people. Canada is already home to one of the best educated workforces in the world, and in an increasingly competitive global economy, more needs to be done to ensure that Canadians can learn, adapt and have good jobs throughout their working lives. Budget 2017's Innovation and Skills Plan advances an agenda to build Canada as a world-leading innovation economy that will create good jobs and grow the middle class. One of the key pillars of this plan is skills and ensuring young Canadians get the skills and experience they need to kick-start their careers.

\section{Can you tell me about the \#kids2030 initiative?}

Kids2030 is a campaign to educate kids on the 17 Global Goals given by the UN. These goals span solving global poverty to gender equality and protection of the environment. KCJ strives to relate as many of our activities as possible around these goals. Through inclusive education KCJ strives to give all kids the power to use technology to make the world a better place. Also, by the year $2030 \mathrm{KCJ}$ will have taught over 1 million kids and 50,000 educators $\mathrm{AI}$ and ethics and how to use technology to achieve the $17 \mathrm{UN}$ Global Goals. 
I was impressed with the teacher training provided by your organization. Do you work with only full-time employees or do you work with volunteers?

KCJ has part-time and full-time employees, as well as volunteer opportunities. As a charity we rely a lot on volunteers in the community for help. Whether that's through supporting events or running Code Clubs in their community!

Do you have different instructors in different parts of the country or do they only travel around the country to help the teachers?

We have instructors in all provinces around Canada, bringing coding lessons into the classroom. If there isn't an instructor near to a classroom then we also provide live, virtual workshops and training. This way we make our programs accessible to as many teachers and students around Canada as possible.

\section{How is Kids Code Jeunesse working during the COVID-19 pandemic?}

We've been fortunate to have so many amazing hard workers at KCJ. Once COVID hit, we were able to work quickly to get all our programs online, like online summer camps for kids to work on fun coding projects from the comfort of their home and online teacher training for teachers who want to continue learning to code to better support their students during this digital shift.

\section{Would you be able to explain more about Code Clubs and Code Club Canada?}

KCJ runs the Canadian chapter of the international Code Club network, working to support clubs in all corners of Canada. Code Clubs are a fun way to keep coding even outside the classroom. They are a happy, safe environment to learn coding with other kids and they are run by volunteers. Anyone can be a volunteer and they don't need any coding experience at all. On the Code Club Canada website, all the lessons are written out with step-by-step instructions on how to code. This makes it really easy and fun for anyone to start coding.

I was also wondering if you are aware of any intentions to expand the work of empowerment of kids, teachers, and parents with technology to other countries? 
We have run several workshops in France and KCJ also supports the French chapter of the Code Club network, which is really exciting, however I'm not sure what's in store for KCJ's global expansion! Maybe Brazil next, if this is an invitation!

Brazil, as a developing country, in 2019, had an estimated 89.8 million smartphone users. In 2018, it was estimated that about 40 percent of the Brazilian population used a smartphone. In 2016, 55.65 percent of the Brazilian population were accessing the internet, most through a smartphone. Do you believe that the empowerment brought with coding can be learned and applied over a smartphone or is that an area in development?

I believe that any access to technology can be an empowerment when used mindfully. Smartphones are an amazing tool to learn coding online. Personally, I am learning html and javascript using a book online through my laptop and smartphone. For the programs that we use at KCJ, there are apps available for micro:bit that can be used on a smartphone but there are still a couple bugs to work out. The app that we use for scratch can be accessed by ipad and smartphones as well. However, I do think that there is more development needed for that as well.

I love the mission of preparing teachers to empower students along with their families. Do you feel that empowering the next generation is the way for a sustainable future?

I definitely do. Empowering younger generations with what we have learned along the way and giving all kids the access to education and technology is the best way to a sustainable future. When you educate all kids (especially girls and kids in underserved communities) then all 17 of the Global Goals are achievable. And I'll add that by working with the adults within a kid's environment, they can help make sure the kids' digital skills progress over time as well.

Even with all the economic and language barriers, I feel that coding (or at least the logic of coding) is a very interesting thing in the sense that it is somewhat uniform all across platforms. Do you believe coding is the language of the future in a way? 
I would agree that coding is the language of the future - it's a real-life application of computational thinking, which is a useful problem-solving approach even for noncomputing problems. Anyone and everyone is capable of learning coding as it is a combination of many different skills. I also think that coding is similar to the concept of math in a way. Math is understood by all even if you speak different languages. It is very universal. I think that coding is similar in that regard.

\section{You are probably familiar with the Sustainable Development Goals (SDGs),} how do you think your work and Kids Code Jeunesse are tackling those goals?

Yes, the SDGs are our organisational guiding light, and the keystone of our \#kids2030 initiative. KCJ works hard to relate all of our activities to these goals and we encourage teachers to do the same. The content or programs that we put out often have a reference to at least one of the goals. For example, a project I designed, using the micro:bit to measure seismic activity, was a great way for the students to think about countries that experience poverty and are hit the hardest with earthquakes. The students also designed earthquake resistant buildings. This is a great way to tackle Global Goal 9 which relates to innovation and industry.

A few of many ways that KCJ tackles these goals in our operations are:

- Using creativity, communication and collaborating to teach kids about coding, we are preparing them with the tools they need to thrive in a challenging world.

- Strategic partnerships with government and industry helps us influence policy and meaningful change.

- Consistently sourcing merchandise from ethical and local suppliers whenever possible.

Recently, international forces of change have prompted hard questions to be asked about what it means to educate for citizenship, do you think Canada is doing a good job in educating for global citizenship?

Yes I do. Canada has a great education system and in the last few years today's young leaders have been standing up to fight for what is right. There have been many positive changes in Canada through environmental change, racial and gender equality. 
I believe that it will only get better especially since kids are being educated to ask big questions and think of new innovative ways to tackle the world's most pressing issues. When I was younger and even in undergrad at university I didn't care much for politics but since then I have been educating myself and staying informed on issues around the world and Canada. I try hard to read and get all the facts before having opinions on an issue and I try to be involved in all issues, even if they don't affect me as much as others. I don't think my case is unique. I think many Canadians, to a more or less degree, are experiencing the same journey as me.

My experience in Canada was of a very multicultural nation and I really enjoyed how I felt viewed as a person and not instantly judged by my accent for example. What do you feel makes Canada so tolerant? - if you agree with the statement, I'd love to hear some of your thoughts.

I agree that I think that Canadians, as a whole, are very kind and embrace all cultures. I think that racism definitely occurs in Canada and with the Black Lives Matter movement occurring all over the world then we need to demand better from everyone and work towards changing our systems which have been built on systemic racism towards people of colour. I'm so glad you had a positive experience when you were in Canada. I really do think that most Canadians are kind and embrace all people who live here. I think that Canada has had a very multicultural past and we have tried to learn from our mistakes of the past: tens of thousands of people have been out protesting against systemic racism during a pandemic! We still have a long way to go but the more people and kids especially who are educated then the better the position we are in to achieve equality with all people.

Another thing that strikes me in Canada is the way they embrace diversity. It seems to me that in all sectors, they seek gender equality, regardless of nationality, including immigrants, etc. It would be interesting to know how this process of welcoming diversity was/has been and to what extent it has fostered/advanced compliance with the SDGs.

I think that Canada still has a ways to go before we have complete equity between all genders and races but I'm very proud of the progress Canadians have made 
over the years. I think that most Canadians are open to change and it only gets better with the younger generations. The younger Canadians are especially open to all people and keen to learn about other cultures. I believe that increased education and access to technology has given us more understanding of others and access to other cultures and people that we never would've had even just a couple decades ago. This has only fostered our love and understanding for other people and cultures in Canada and the rest of the world.

I see Canada as a leader in AI, do you feel that this leading role also helps in accomplishing the Global Goals?

I do. When people use technology with more of a mindful understanding of how it works then they are able to ask bigger questions. Once you ask those questions then you become an innovator and not just a user. We need more kids to become innovators of technology and not just a user. When we innovate then this leads to countless possibilities and access to technology to more people. It's a cycle that doesn't stop till all people around the world can have access to the same opportunities.

\section{How do you think Canada is preparing the next generation for global citizenship?}

More and more companies and industries are beginning to have similar values to KCJ, where all kids should be given access to technology and given the skills to make the future brighter. This is preparing the next generation to be innovators of technology and to use technology to solve meaningful problems that affect humans all over the world. Younger generations are learning to be more thoughtful and collaborative with others around the world, which will make them better global citizens than older generations ever were.

Is there anything else you would like to add about the topics of coding, SDGs, and education?

People can learn more about KCJ at www.kidscodejeunesse.org, and they can read about our AI \& SDG initiative at www.kidscodejeunesse.org/kids2030. We send out a monthly newsletter and post regular updates about events, resources and stories 
from our community on facebook, instagram, linkedin, twitter \& youtube. And we have more virtual Teacher Trainings coming up in both French \& English!

Note

${ }^{1}$ LL.B Student at Alto Vale do Rio do Peixe University, Caçador, Santa Catarina, Brazil. juniorklaus8@gmail.com 